\title{
População tradicional, adaptações culturais e o ecoturismo
}

\author{
Traditional population, cultural adaptations and ecotourism
}

\section{Tarita Schnitman}

\begin{abstract}
RESUMO
O trabalho apresenta uma discussão sobre a prática do ecoturismo por população tradicional. O ecoturismo é uma atividade econômica e seu desenvolvimento em população tradicional demanda algumas reflexões. Torna-se importante identificar a realidade social da comunidade e as transformações culturais decorrentes da atividade turística. O trabalho investiga esses aspectos em uma população tradicional brasileira.
\end{abstract}

PALAVRAS-CHAVE: População Tradicional; Transformações Culturais; Ecoturismo.

\begin{abstract}
This paper presents a discussion over ecotourism in traditional population. Ecotourism is just like any other economic activity and its development in a traditional population demands some reflection. It is important to identify the social reality of the community and cultural transformations caused by tourism. The work investigates these aspects in a traditional brazilian population.
\end{abstract}

KEYWORDS: Traditional Population; Cultural Transformations; Ecotourism.

\section{Introdução}

Observa-se que nos últimos anos há um crescente aumento da prática do turismo por populações tradicionais. Esse fato é ocorrente na região Amazônica, por exemplo, onde existe o Projeto Ecoturismo na Unidade de Conservação do Parque Nacional do Monte Roraima (NOGUEIRA et al, 2013). Na região do Vale do Ribeira no Estado de São Paulo a população tradicional remanescente de quilombo do Mandira desenvolve a atividade turística. Os Mandiranos obtiveram o reconhecimento de suas terras como território quilombola, uma extensão de 2.054,65 ha de terra (ITESP, 2002). A comunidade está localizada no litoral sul do Estado de São Paulo e situa-se em bairro da cidade de Cananéia. O termo "quilombola" é aplicado a toda comunidade negra rural que agrupa descendentes de escravos que vivem em uma cultura de subsistência e suas manifestações culturais têm forte vínculo com o passado. O art. 216 da Constituição Brasileira de 1988 expressa:

Página 1016 Revista Brasileira de Ecoturismo, São Paulo, v.6, n.5, nov 20I3-jan 20I4, pp.I0I6-I027. 
Constituem patrimônio cultural brasileiro os bens de natureza material e imaterial, tomados individualmente ou em conjunto, portadores de referência à identidade, à ação, à memória dos diferentes grupos formadores da sociedade brasileira, nos quais se incluem: I - as formas de expressão; II - os modos de criar, fazer e viver; III - as criações científicas, artísticas e tecnológicas; IV - as obras, objetos, documentos, edificações e demais espaços destinados às manifestações artísticoculturais; V - os conjuntos urbanos e sítios de valor histórico, paisagístico, artístico, arqueológico, paleontológico, ecológico e científico.

Uma população tradicional possui modo de vida próprio e se reconhece como pertencente à um grupo social particular (DIEGUES,1998). Para Carneiro Cunha (2009) as populações tradicionais usam de técnicas ambientais de baixo impacto, formas equitativas de organização social, presença de instituições com legitimidade para fazer cumprir suas leis, possuem liderança local e traços culturais que são seletivamente reafirmados e reelaborados. Diegues (1998) enfatiza aspectos importantes inerentes a população tradicional como o modo de produção pré-capitalista onde o trabaIho não é mercadoria. Para o autor, essas populações desenvolvem pequena produção mercantil e em suas formas de produção, o trabalho assalariado é ocasional, não sendo determinante. Prevalece o trabalho autônomo ou familiar. A necessidade do mercado é real, mas não total. As formas de manejo dos recursos naturais por parte dessas populações não visam diretamente o lucro, mas a reprodução social e cultural. A pequena capacidade de acumulação de capital dificulta a emergência de classes sociais. Ou seja, esses aspectos são distintos do modo de viver moderno coberto de conflitos de interesses e de impessoalidade nas relações sociais. A sociedade moderna invoca individualismo, competição e lucratividade. Por exemplo, em suas pesquisas Diegues (1998) encontrou relações sociais baseadas na solidariedade e na cooperação em comunidades tradicionais do litoral do Estado de São Paulo. O autor percebeu que essas relações determinam as formas de produção e marcam a distribuição de trabalho individual ou coletivo. As festas, lendas, a religião e a simbologia mítica não são somente valores cognitivos, mas também afirmam a coesão social das mesmas. As populações tradicionais possuem atividades econômicas de pequena escala como extrativismo, pesca, artesanato, coleta e agricultura. Geralmente são de baixa densidade populacional e limitado desenvolvimento tecnológico. Esses aspectos fazem com que sua interferência no meio ambiente seja pequena. No Brasil o remanescente de florestas é encontrado em regiões onde houve pouca urbanização e falta de acesso a tecnologia, unidos a uma convivência mais harmoniosa entre populações tradicionais e natureza. Isso notoriamente ocorre na região Amazônica onde indígenas vivem há muitos anos e em bolsões de Mata Atlântica no Vale do Ribeira, entre outros territórios.

Muitas comunidades quilombolas mantêm a reprodução social e as atividades tradicionais. Famílias permanecem no campo com suas relações de solidariedade e mutirões. A religiosidade marca o calendário anual e festas típicas. Algumas dessas comunidades encontram-se em áreas de difícil acesso como no caso da comunidade Areia Branca do Vale do Ribeira. Nessa comunidade, as famílias organizam-se em cooperativa para a comercialização de produtos provenientes da agricultura familiar 
cultivados de forma ecológica (COOPERAFLORESTA, 2013).

Naturalmente, ao longo dos anos, as populações tradicionais passaram por transformações. Elas foram pressionadas pela escassez de recursos naturais que antes eram abundantes e faziam parte da dieta alimentar, do material de construção, do medicamento utilizado, entre outros. Muitas tiveram seus territórios diminuídos ou cercados por cidades. Áreas de parque com proibições de uso foram demarcadas em sobreposição do território ou foram invadidas por grileiros e imobiliárias. Muitas populações tradicionais do Vale do Ribeira, por exemplo, mudaram de atividade de agricultura de subsistência para atividade comercial. Neste caso inclui-se a comunidade do Mandira que implantou uma cooperativa de comercialização de ostras. Dessa maneira surgiram transformações na cultura local.

Essas transformações podem ser vistas sob a forma de impacto ambiental.

O impacto ambiental é definido como: [...] qualquer alteração das propriedades físicas, químicas e biológicas do meio ambiente, causada por qualquer forma de matéria ou energia resultante das atividades humanas que, direta ou indiretamente, afetam: a saúde, a segurança e o bem-estar da população; as atividades sociais e econômicas; a biota; as condições estéticas e sanitárias do meio ambiente; a qualidade dos recursos ambientais (BRASIL, RESOLUÇÃO CONAMA 01, 1986, p.1).

Impactos sociais, por exemplo, são facilmente identificados em qualquer território que decide inserir uma nova atividade econômica. A atividade turística é um exemplo. Segundo Januário (1997), o turismo é um fato coletivo que produz o desenvolvimento de instituições, relações sociopolíticas e econômicas complexas; um conjunto de questões financeiras, culturais e de relações psicossociais, intrinsecamente relacionadas. Sendo assim, a atividade turística envolve muitos atores sociais que dialogam e causam ações nos seus setores distintos. Não obstante, os impactos sociais da atividade turística são comuns. Eles podem ser a introdução do crime, drogas, alcoolismo, rompimento de laços de solidariedade (TOSUN, 2002).

Entretanto, o ecoturismo é um segmento que objetiva minimizar os impactos sociais e ecológicos decorrentes da atividade turística em determinado destino. O que diferencia o ecoturismo dos demais segmentos do turismo é a aplicação dos seus princípios e valores éticos (WALLECE; PIERCE, 2009). Estar em local protegido e a adequação aos conceitos de sustentabilidade (ORAMS,1995) e o aspecto educacional da atividade. O segmento é apropriado para pequenas comunidades, reservas de desenvolvimento sustentável, entorno de áreas de rica cultura e natureza. Segundo Ceballos-Lascurain (1999), os ecoturistas tentam fazer com que suas experiências causem o menor impacto ambiental e cultural possível.

Não obstante, o reconhecimento de populações tradicionais e o direito a terra é um tema conflitivo no Brasil. Muitas populações tradicionais encontram-se em parques de visitação turística ou em seus entornos. Por pressões do desenvolvimento seus territórios tendem a diminuir ao longo dos anos. Por isso, há uma limitação e

Página 1018 Revista Brasileira de Ecoturismo, São Paulo, v.6, n.5, nov 20I3-jan 20I4, pp.1016-1027. 
crescente demanda em estudos mais aprofundados sobre o turismo nessas populações. Por exemplo, não se sabe claramente sobre os efeitos na cultura local quando uma população tradicional desenvolve a atividade turística. Este trabalho investiga estas condições na comunidade do Mandira.

\section{Material e Métodos}

O referencial teórico utilizado para o trabalho está cunhado em estudos antropológicos. Na metodologia foi importante aplicar o estudo de caso. Segundo Chizzotti (2001) este método apresenta a vantagem por desvelar aspectos fundamentais para a solução do problema da pesquisa e por evidenciar novas descobertas.

O estudo de caso foi realizado em Mandira onde a agricultura familiar, o cultivo de ostras e o turismo são atividades importantes para seus residentes. Atualmente a comunidade possui 23 famílias. Geograficamente o Parque Estadual do Jacupiranga é entorno e limita-se na margem direita do rio Mandira. O território está em Área de Proteção Ambiental Federal Iguape-Peruíbe-Cananéia e engloba zonas de amortecimento do Parque Estadual do Lagamar de Cananéia e do Parque Estadual da Ilha do Cardoso e (GOUVEIA, 2010). A Reserva Extrativista Mandira localiza-se no complexo estuarino lagunar de Iguape-Cananéia-Paranaguá (MMA, 2010) e os residentes de Mandira são seus beneficiários, permitidos a cultivar ostras e extrair recursos naturais de forma equilibrada do manguezal. Esse fatores mostram que o território está sob preservação ambiental e a população de Mandira é tradicional remanescente de quilombos. O trabalho averigua as modificações culturais e impactos socias da atividade ecoturística na comunidade quilombola Mandira. Coletou-se dados sobre a atividade turística na comunidade. Como processo metodológico utilizou-se de revisão bibliográfica sobre turismo no Vale do Ribeira, agricultura familiar e impactos sociais. Para a discussão dos impactos sociais foi utilizada como referência a tabela de Tosun (2002) que determina fatores para percepções de impactos sociais do turismo. Os instrumentos metodológicos escolhidos foram entrevistas semi-estruturadas, diário de campo e observação. Eles forneceram subsídios à alguns fatores sociais retirados da tabela de Tosun como crime, vício em drogas, alcoolismo, abertura sexual, oportunidades de trabalho, e relações de solidariedade.

Todas as 23 famílias Mandiranas foram entrevistadas.Grupos de turistas foram acompanhados e informações relevantes foram inseridas ao diário de campo. Ocorreram visitas de campo em 2011, 2012 e 2013 em diferentes épocas do ano como o feriado de Páscoa, o mês de férias de Julho em 2011 e 3 visitas no ano de 2012 e dois períodos de Carnaval.

\section{Resultados}

Para realizar uma análise aprofundada do tema foi relevante contextualizar a comunidade dentro do seu território e da história da região. As transformações na cultura da população de Mandira remontam ações governamentais na região. No século XX a região do Vale do Ribeira foi relegada a um processo de isolamento devido à implantação da monocultura do café que redirecionou a alocação dos recursos do go- 
verno para outras regiões do Estado. Ou seja, o processo de industrialização foi mínimo neste território. Após a construção da BR-116, empresas de mineração foram implantadas na região. Nos anos de 1980, o governo executou uma série de obras sem consultar os moradores tradicionais. Também criou Unidades de Conservação na região como o Parque Estadual da Serra do Mar e Parque Estadual Carlos Botelho (TODESCO,2007). Desprezou sistematicamente as populações tradicionais que tiveram os seus limites decretados em sobreposição às Unidades de Conservação. $O$ plantio tradicional das roças de coivara, método que utiliza a corte e queima, foi proibido devido ao risco ambiental às áreas decretadas para preservação ambiental. $\mathrm{O}$ uso dos recursos naturais historicamente explorados também foi restrito. A proibição do acesso aos recursos naturais tradicionalmente explorados por caiçaras, indígenas e quilombolas que habitavam a região resultou em um extrativismo predatório para o suprimento de novas indústrias como a de palmito, madeiras e camarões. As ações governamentais acabaram determinando uma valorização das terras decorrendo em um sério processo de especulação imobiliária e grilagem de grandes áreas. Todos esses fatores eclodiram no êxodo dos moradores rurais e litorâneos do Vale do Ribeira. Por outro lado, também facilitou a chegada de outras pessoas à região e a formação de novos empreendimentos imobiliários, alimentícios, turísticos e madeireiros que não possuíam vínculo com a região e a preocupação com o equilíbrio dos recursos naturais. Nesse período causaram-se danos piores que os séculos de ocupação caiçara, ribeirinha, indígena e quilombola.

Outras transformações culturais ligadas ao incremento da atividade turística em prol do desenvolvimento desta região remontam o ano de 1995. A Empresa Brasileira de Turismo- EMBRATUR criou o projeto "Pólo Ecoturístico do Lagamar" na região de Cananéia. Com o apoio da WWF, a ONG Vitae Civillis executou o projeto "Turismo Sustentável" com o objetivo de preservar a Mata Atlântica. Entre os anos de 1995 e 1999 a Agenda de Ecoturismo do Vale do Ribeira realizou fóruns e oficinas de capacitação em ecoturismo para a população local com o apoio do Senac e do Instituto de Ecoturismo do Brasil (TODESCO,2007). Cursos foram direcionados aos agentes municipais e aos 450 monitores ambientais. A Agenda foi patrocinada pela EMBRATUR e coordenada pela Fundação Florestal (idem). Em 2000 ocorreu o Primeiro Encontro de Ecoturismo do Vale do Ribeira. Já em 2004, o Consórcio de Segurança Alimentar e Desenvolvimento Local do Vale do Ribeira- CONSAD instituiu uma câmara técnica de turismo. Algumas ONGs realizaram cursos de turismo para comunidades e famílias de agricultores familiares. Porém, o maior projeto que aconteceu na região foi no ano de 2005, o "Programa de Desenvolvimento do Ecoturismo na região da Mata Atlântica", uma parceria entre o BID e o governo do estado de São Paulo.

A comunidade do Mandira se beneficiou de alguns dos projetos citados anteriormente. Participa do Circuito de Turismo da Agricultura Familiar de Cananéia. Segundo Martins et al. (2009) o turismo rural com foco na agricultura familiar ocorre no município de Barra do Turvo e no Circuito de Turismo da Agricultura Familiar de Cananéia. Atualmente o roteiro de Agricultura Familiar de Cananéia agrega poucos agricultores, porém, os Mandiranos continuam recebendo turistas. A comunidade também faz parte do Circuito Quilombola do Vale do Ribeira. Este circuito foi desenvolvido em

Página 1020 Revista Brasileira de Ecoturismo, São Paulo, v.6, n.5, nov 20I3-jan 20I4, pp.1016-1027. 
algumas comunidades como André Lopes, Ivaporunduva, Mandira, Pedro Cubas, $\mathrm{Pe}-$ dro Cubas de Cima, São Pedro, Sapatu. Seu objetivo é incrementar a geração de renda nas comunidades e, ao mesmo tempo, possibilitar o visitante conhecer a história de luta dos quilombos pela manutenção de sua cultura e de seus territórios. O lançamento do Circuirto Quilombola do Vale do Ribeira ocorreu em São Paulo no dia 11 de setembro de 2012 no SESC São Paulo quando foram convidadas operadoras e agências de turismo do trade turístico.

Desde 1868 os Mandiranos, residentes de Mandira, vêm produzindo e reproduzindo sua cultura material e simbólica. Sendo uma população rural tradicional, segmento social específico, dotado de uma identidade política. Suas raízes remontam de uma determinada relação social historicamente datada, a escravidão. Os principais cultivos eram a mandioca, batata doce, cará, cana, feijão, milho e arroz, sem o uso de agrotóxicos. A identidade grupal está fundamentada tanto pelas redes de sociabilidade calcadas no parentesco quanto nas relações de trabalho que o grupo mantém com a área que ocupa. Os laços familiares e o apego das famílias às suas terras na comunidade do Mandira garantem o desenvolvimento de atividades produtivas. Dados do Relatório Técnico Científico do Estado de São Paulo (SÃO PAULO, 2002) e relatos de entrevistas revelam uma agricultura comunitária em Mandira onde as famílias se ajudavam mutuamente. Os mutirões de plantio e colheita eram frequentes, havia um coletivo agricultor. Esta comunidade tradicional nunca viveu descontextualizada da produção agrícola regional. Recriaram formas de viver que incluem novas atividades produtivas incrementadas por experiências tecnológicas e organizacionais como o cultivo de ostras e o turismo. Cabe neste momento destacar as atividades e projetos que ocorreram na comunidade para o melhor entendimento do processo de adaptação às mudanças e às novas realidades (Quadro 1).

Os dados do Quadro 1 destacam diversos projetos, interferências governamentais e privadas, cursos e capacitações em Mandira. A comunidade remanescente de quilombos do Mandira caracteriza-se como população tradicional com fortes interações com o mercado, já que muitos dos seus moradores participam da cooperativa de ostras. Também integram feiras regionais como o Salão de Turismo em São Paulo e Revelando São Paulo. Turistas visitam a anual Festa da Ostra. A comunidade recebe turistas em distintas épocas do ano provenientes de escolas e universidades, pessoas da região e grupos interessados na organização social da comunidade. As famílias comercializam ostras durante festas tradicionais, feiras regionais e ao longo da visitação turística. Há um restaurante e um bar que oferece refeições a base de ostras e os visitantes podem passear de barco pelo manguezal da Reserva onde as ostras são cultivadas em viveiros. O galpão de artesanato é um atrativo turístico e ponto de venda do artesanato local e outros produtos. Um grupo de mulheres reunidas administram as vendas, encomendas e a produção do artesanato. A cachoeira do Mandira, a agrofloresta, uma ruína histórica da época da escravidão e sambaquis englobam as atrações locais. Além desses atrativos, os turistas se interessam pela história da comunidade e sua organização 


\begin{tabular}{|c|c|}
\hline \multicolumn{2}{|r|}{$\begin{array}{l}\text { Quadro 1: Histórico de acontecimentos em Mandira. } \\
\text { Table 1: History of events in Mandira (SP, Brazil). }\end{array}$} \\
\hline 1989 & A comunidade foi escolhida para ser uma zona de pesca e coleta controlada pelo pla- \\
\hline 1994 & Projeto conhecido como "ostra de Cananéia" realizado entre o Instituto de Pesca APT- \\
\hline 1995 & Criação da Associação Reserva Extrativista dos Moradores do Bairro do Mandira - \\
\hline 1997 & $\begin{array}{l}\text { Subprojeto "Manejo dos Bancos Naturais de Ostras, Depuração e Comercialização do } \\
\text { PED. Cadastramento das comunidades extratoras. Criação da cooperativa. Mutirão } \\
\text { realizado para construir a depuradora da COOPEROSTRA. Projeto "Engorda de Os- } \\
\text { tras" realizado pelo Instituto de Pesca APTA/SAA, PED e ONG Gaia Ambiental. Mandi- } \\
\text { ra recebe curso sobre engorda de ostra. }\end{array}$ \\
\hline $\begin{array}{l}1999 \\
2001\end{array}$ & $\begin{array}{l}\text { Financiamento da Shell do Brasil. Aporte técnico e financeiro do Fundo Brasileiro para } \\
\text { a Biodiversidade-FUNBIO. Recursos doados pelo Fundo Global para o Meio Ambiente. } \\
\text { Propôs o ordenamento da exploração da ostra de mangue, coordenado pela Fundação }\end{array}$ \\
\hline 2000 & COOPEROSTRA entra no mercado Paulista. \\
\hline 2002 & $\begin{array}{l}\text { COOPEROSTRA foi indicada como finalista para o prêmio Iniciativa Equatorial } 2002 \\
\text { organizado pelas Nações Unidas. O presidente da COOPEROSTRA participou da Cú- } \\
\text { pula Mundial para o Desenvolvimento Sustentável }(\mathrm{RIO}+10) \text { na África do Sul. COO- }\end{array}$ \\
\hline 2005 & $\begin{array}{l}\text { Implantação do- Projeto Demonstrativo-PDA I e II chamado "Estruturação da Reserva } \\
\text { Extrativista do Mandira". A Associação de moradores de Mandira - REMA é a propo- } \\
\text { nente. COOPEROSTRA é beneficiada com capacitação dos cooperados e seus filhos }\end{array}$ \\
\hline
\end{tabular}

Fonte: Adaptado por Tarita Schnitman de Garcia (2005).

Source: Adapted by Tarita Schnitman from Garcia (2005).

\section{Discussão}

Segundo Diegues (1998) o fortalecimento da identidade sociocultural advém de seu auto-reconhecimento, sendo uma identidade construída ou reconstruída, um resultado de processos de contatos conflitivos com a sociedade urbano-industrial e com os neomitos criados por esta. As culturas tradicionais estão sempre intercambiando informações com outras culturas. Não se pode falar de aculturação de população tradicional nos tempos atuais onde o universo de contatos interculturais é enorme.Todo ser humano ao vir ao mundo encontra-se no interior de uma complicada trama de costumes, sistemas relacionais e instituições. A cultura pode ser considerada uma herança social das pessoas permitindo a convivência em comunidade ao ponto que ensina a prever o comportamento do próximo e o que é esperado de cada membro. Pode-se refletir sobre a cultura como uma lente através da qual enxerga-se e avalia-se o mundo. Sendo assim, um complexo saber coletivo acumulado em memória social possuidora de uma visão de mundo. As comunidades tradicionais estão constantemente se relacionando ou brigando com a sociedade moderna. Segundo Durham (2004), toda sociedade, por força de sua reprodução, deve saber enfrentar a mudanças. Também que as sociedades comunitárias são forçadas a entrar em contato com a a sociedade moderna tradicional. Para Cuche (2004) não existem de um lado as

Página 1022 Revista Brasileira de Ecoturismo, São Paulo, v.6, n.5, nov 2013-jan 20I4, pp.1016-1027. 
culturas puras e de outro, as culturas mestiças. Todas, devido ao fato universal dos contatos culturais, são, em diferentes graus, culturas mistas, feitas de continuidades e descontinuidades. Para Laraia (1986), o domínio mais adaptativo da cultura é a tecnologia, a economia de subsistência e os elementos de organização social diretamente ligadas à produção. Ou seja, essas populações não se aculturam, mas passam por um processo de adaptação e regeneração, onde as mudanças são bastante presentes. Esse processo é nítido em Mandira, por exemplo, os Mandiranos aprenderam a gerir uma cooperativa e também recepcionar turistas.

Em relação ao turismo, durante a visitação turística, a história da comunidade é contada. Quando isso ocorre, há um resgate cultural. Os moradores entendem que é importante valorizar a história do seu povo. Maluf e Carneiro (2003) citam que a manutenção do tecido social decorre de fatores ligados à identidade social e às forças de sociabilidade das famílias. Esses fatores são perceptíveis em Mandira, pois as famílias possuem laços sociais e uma identidade coletiva. Essas condições foram fundamentais no processo reconhecimento como população tradicional perante o Governo do Estado de São Paulo e para a obtenção de direitos ao uso da terra e o acesso à políticas públicas. A divulgação da comunidade e a atividade turística em si também agem em consonância com esse processo. Dentro de tudo, com o ecoturismo gera-se o reconhecimento de papéis desempenhados pela população e suas tradições.

A mulher desempenha funções no receptivo turístico, na alimentação, no artesanato. O ecoturismo estimula o processo de valorização das tradições, da culinária, artesanato e da história. Para receber as atividades ecoturísticas, a comunidade reorganiza suas unidades de produção com vistas a implantar novos serviços como o processamento de alimentos e o artesanato. Novas fontes de renda são criadas. A venda de ostras, do artesanato, produtos alimentícios e produtos vendidos em feiras complementam a renda mensal aumentando a autoestima das pessoas e valorizando o estilo de vida local. Refeições caseiras a base de peixe fresco, ostras, arroz e feijão são oferecidas aos turistas. A valorização da comida local é um atrativo turístico emaranhado de estórias e lembranças. Em certas ocasiões o cuscuz de arroz pilado é servido. Alguns turistas procuram a tradicional cachaça com folhas de cataia, planta nativa da Mata Atlântica.

Contudo, as pessoas envolvidas com a atividade turística precisam se adaptar aos novos horários de trabalho e as demandas dos turistas. O receptivo é diferente do cultivo de ostras e também da agricultura familiar, a atividade tradicional. Precisa-se atender aos horários de chegada, almoço, saída dos turistas. A relação com o turista envolve uma troca de ideias e muitas vezes o morador é introduzido à uma nova forma de olhar o mundo. Também há que ser gentil e cordeal com os visitantes. Por exemplo, alguns Mandiranos entrevistados citaram que o turismo ajudou a trabalhar a vergonha e a timidez de falar com pessoas estranhas. Esses aspectos demonstram que houve uma transformação de atitude e comportamento dos moradores com a inserção do turismo na comunidade.

As observações de campo e entrevistas identificaram que os impactos sociais em Mandira são controlados naturalmente pela organização social, os laços de identi-

Página 1023 Revista Brasileira de Ecoturismo, São Paulo, v.6, n.5, nov 2013-jan 20I4, pp.10I6-1027. 
dade e parentesco. Os Mandiranos percebem suas conquistas, valorizam a comunidade e o fato de serem guardiões da reserva extrativista. As pessoas se conhecem e moram próximas umas das outras. Por esses motivos, não há na comunidade problemas com o turismo sexual e drogas. Isso também se justifica pelo perfil dos turistas que são em grande maioria estudantes e pesquisadores. Crimes e atos violentos com o turista decorrentes da atividade turística também não foram identificados ou citados por moradores. Ao contrário, os Mandiranos relatam que gostam da atividade turística. Entrevistas com todas as famílias revelam as características da atividade turística em Mandira (Quadro 2).

Quadro 2: impactos sociais do turismo em Mandira.

Table 2: social impacts of tourism in Mandira (SP, Brazil).

\begin{tabular}{|l|c|}
\hline \multicolumn{1}{|c|}{ Aspectos do Turismo em Mandira } & Número de pessoas \\
\hline Aumento de Renda & 7 \\
\hline Troca de Informação com Turistas & 3 \\
\hline Estimula a Ganância & 3 \\
\hline Estimula a União entre pessoas & 3 \\
\hline Valoriza o Artesanato & 1 \\
\hline Preserva a Natureza & 1 \\
\hline Causa Alegria & 23 entrevistados \\
\hline Total: & \\
\hline
\end{tabular}

Fonte: Autora. Source: Author.

Considerando estes dados, percebe-se a importância do ecoturismo neste território envolto de áreas protegidas e restrições ambientais onde seus moradores foram proibidos de praticar suas atividades tradicionais e incentivados a comercializar a ostra de forma cooperativa.

Entretanto, anteriormente no trabalho foram citados os projetos turísticos para - Vale do Ribeira e a determinação do governo e ONGs em tornar a região um destino ecoturístico. A comunidade do Mandira se beneficiou com os diversos projetos, capacitações e aportes financeiros implementados ao longo dos últimos anos. A COOPEROSTRA causou mudanças. As interferências governamentais e de ONGs enquanto projetos desenvolvimentistas desorganizaram a cultura dessa população tradicional. Ocorreram modificações culturais. Essas transformações envolveram novas atividades econômicas que demandaram mudanças de comportamento e mais contato com o mercado.

Porém, esse processo tem origem na uniformização cultural, na globalização e na cultura de massa. O processo em sua essência reside no capitalismo que se alastra. A grande maioria das populações tradicionais brasileiras estão articuladas com 0 
mercado e o processo de adaptação cultural é algo contínuo. As populações tradicionais são forçadas a conviver com a sociedade moderna.

Este é o caso da comunidade do Mandira que explora a ostreicultura, o turismo e a venda de produtos da agricultura familiar. O ecoturismo é uma atividade econômica causadora de transformações e impactos sociais, mas os Mandiranos já absorveram hábitos urbanos e a necessidade do acúmulo de bens materiais, aliás, como muitas comunidades tradicionais por todo o Brasil. Dessa forma, a palavra aculturação em Mandira é inapropriada, complicada e conflitiva. Segundo Perrot (2008), recusar o desenvolvimento é assumir seu próprio destino e não estagná-lo ou retardá-lo. Ou seja a cultura Mandirana foi aperfeiçoada, acomodada por seus moradores às necessidades e exigências do mercado.

\section{Conclusões}

Torna-se uma tarefa difícil avaliar o efeito do ecoturismo em comunidades tradicionais, isso depende das condições de cada território e de suas relações com o mercado e a vida urbana. Por esse motivo, é importante considerar que muitas comunidades remanescentes de quilombo do Estado de São Paulo estão localizadas no centro econômico do Brasil, sendo muito difícil isolá-las de um capitalismo crescente. A grande pressão governamental e de ONGs em inseri-las no mercado mostra-se nos tantos projetos desenvolvimentistas citados no trabalho. Muitos desses projetos estimularam a atividade turística em parques e territórios quilombolas, pois há um forte interesse em desenvolver a região. $O$ ecoturismo é uma atividade econômica e é incoerente ignorar os interesses capitalistas por trás dela.

Por outro lado, o trabalho também demonstra que a cultura é flexível e passível de transformações, sendo esse um consenso entre antropólogos respeitados. Ou seja, a atividade turística é exógena, causadora de impactos sociais, mas pode ser um tanto benéfica para a comunidade tradicional em forma de resgate cultural e reprodução social. Também um fator de reconstrução social, melhoramento das condições de vida da comunidade e preservação ambiental. O ecoturismo resgata o modo de vida garantindo à homens e mulheres referências sociais que reorganizam ou reconstroem costumes e tradições. Para a comunidade quilombola Mandira o seu território que se tornou destino turístico é um locus de representações e do imaginário mitológico, mas também espaço de reprodução econômica, das relações sociais e o resgate de todo um sentido cultural.

Porém, uma comunidade quilombola passará por transformações profundas com o desenvolvimento da atividade turística se o consumismo não está alocado na essência das pessoas e as relações com o mercado são ainda incipientes. $O$ turismo poderá prejudicar a cultura local. Entretanto, se uma comunidade tradicional não se insere nestas circunstâncias e está bem adaptada ao mercado, ressalta -se a importância do planejamento coletivo e participativo da atividade turística. O turismo de base comunitária é apropriado. 


\section{Referências bibliográficas}

BRASIL. CONSTITUIÇÃO BRASILEIRA: 1998.

BRASIL. Ministério do Meio Ambiente. Plano de Manejo Participativo Reserva Extrativista do Mandira Cananéia/São Paulo:2010.

CARNEIRO CUNHA, M. Cultura com aspas, outros ensaios. Cosac Naify, São Paulo:2009.

CEBALLOS-LASCURAIN. Tourism, Ecotourism and Protected Areas: The State of Nature-Based Tourism around the World and Guidelines for its Development. Gland: IUCN,1999.

CHIZZOTTI, A. Pesquisa em Ciências humanas e sociais. São Paulo:Cortez, 2001. COOPERAFLORESTA. Agrofloresta: agricultura em harmonia com a natureza. Barra do Turvo. São Paulo. 2013. Folder.

CUCHE, D. A noção de cultura nas ciências sociais. EDUSC, Bauru: 2004.

DIEGUES, A.C.S. O Mito Moderno da Natureza Intocada. Hucitec, SP:1998

DURHAM, E.R. A dinâmica da cultura: ensaios de antropologia. Cosac Naify, SP: 2004.

GARCIA, T.R. Impactos da Implantação da Cooperostra. Dissertação de Mestrado. Faculdade de Zootecnia e Engenharia de Alimentos da Universidade de São Paulo,Pirassununga:2005.

GOUVEIA, J.M.C. A Métrica da Sustentabilidade na Perspectiva da Geografia: aplicação e avaliação do painel da sustentabilidade (Dashboard of Sustainability) na comunidade Quilombola do Mandira Cananéia-SP. Tese de Doutorado. Faculdade de Filosofia, Letras e Ciências Humanas da Universidade de São Paulo, São Paulo:2010.

ITESP. http: www.itesp. sp.gov.br (2002). Acessado em Maio de 2012.

JANUÁRIO, S.S. O desenvolvimento turístico como catalisador da organização sociopolítica local. Florianópolis: 1997, pag.15.

LARAIA, R.B. Cultura: Um conceito Antropológico. Zahar, Rio de Janeiro:1986.

MALUF, R.S.; CARNEIRO, M.J. (orgs). Para Além da Produção, multifuncionalidade e Agricultura Familiar. Rio de Janeiro: Maud, 2003.

MARTINS, A.B.M et al. Promovendo os direitos de mulheres, crianças e jovens de comunidades anfitriãs de turismo do Vale do Ribeira São Paulo: Instituto Ing_Ong de Planejamento Socioambiental, 2009.

NOGUEIRA, E.M.; COSTA-NETO, C.P.L.; SILVA, G.P. Qualificação profissional como suporte para implantação do etnoturismo na comunidade indígena Ingarikó (RR). Revista Brasileira de Ecoturismo, São Paulo, v.6, n.2, mai/jul-2013, pp.424-441.

ORAMS, M.B. Towards a More Desirable Form of Ecotourism, Tourism Management 16(1): 3-8:1995. 
PERROT, D. Quem Impede o desenvolvimento "circular"? (Desenvolvimento e povos autóctones:paradoxos e alternativas). Cadernos de Campo. São Paulo: 2008.

SÃO PAULO. Relatório Técnico Científico sobre os Remanescentes da Comunidade de Quilombo de Mandira/Cananéia-SP. Governo do Estado de São Paulo. 2002

TODESCO, C. Estado e Terceiro Setor na Organização do Espaço para o Turismo no Vale do Ribeira. Dissertação de Mestrado. USP, São Paulo, 2007.

TOSUN, T. Host Perceptions of Impacts: a comparative Tourism Study. Annals of Tourism Research, Vol. 29, No. 1, pp. 231-253, 2002.

WALLACE, G.N.,PIERCE, S.M, An Evaluation of Ecotourism in Amazonas, Brazil. Annals of Tourism Research, 2009.

Tarita Schnitman: Universidade de São Paulo, Piracicaba, SP, Brasil.

Email: taritaturismo@yahoo.com.br

Link para o currículo Lattes: http://lattes.cnpq.br/3269551003610588

Data de submissão: 02 de janeiro de 2013

Data de recebimento de correções: 01 de julho de 2013

Data do aceite: 04 de julho de 2013

Avaliado anonimamente

Página 1027 Revista Brasileira de Ecoturismo, São Paulo, v.6, n.5, nov 2013-jan 20I4, pp.10I6-1027. 